Background Recent data demonstrated that surgical clipping of the middle cerebral artery aneurysm may be superior to endovascular coiling when modified Rankin Scale (mRS) 2 or less is considered a good outcome. However, it is not clear that how many of the patients in both arms were able to go back to baseline functional states despite being independent. There are minimal data on the outcome of the repair of the MCA aneurysm when mRS $0-1$ is considered a good outcome. Additionally, outcome of patients with a complex anatomy and/or wide neck are not well described.

Objectives Primary objective is to evaluate the functional outcomes of MCA aneurysm patients who underwent endovascular repair including those with wide neck and complex in nature. Secondary, objective is to determine the percentage of good outcome (mRS 0-2) patients who may return to the functional status (mRs $0-1)$.

Methods From a prospectively maintained database, consecutive patients with MCA aneurysm who underwent endovascular treatment were enrolled from 2011 to 2015. Patient's demographics including perioperative events were captured. In addition to the long-term angiographic results, the functions outcome was measured using mRS in 90 days and subsequent visits.

Results 13 patients with median age 60 years (38-76), 83\% women underwent endovascular repair of the 14 MCA aneurysms. Off 14 aneurysms (right 9) including 2 ruptured cases (11 were wide neck and 6 had complex anatomy), 11 required stent-assisted coiling representing one ruptured case. Stent was deployed in all but one case due to the extreme tortuosity, which underwent primary coiling of aneurysm. This 67 years old patient with $14 \mathrm{~mm}$ symptomatic right MCA aneurysm required treatment prior to initiate chemo and radiation therapy for her breast carcinoma. She developed intraoperative thrombosis of superior division of MCA which was recanalised using $10 \mathrm{mg}$ of intra-arterial eptifibatide resulted in no clinical symptoms or radiographic stroke. Immediate complete and near complete obliteration was observed in 10 and subtotal in 4 cases. One patient lost long term follow-up. Off 4 subtotal cases; two achieved complete and 2 remain subtotal with improvement. Recurrence of aneurysm was observed in two cases that required subsequent coiling and achieve long-term complete obliteration. 90 days Independent functional outcome (mRS 0-2) was observed in all 13 patients including 2 ruptured cases. Long-term normal functional state (mRS 0-1) was observed in 11/12 cases and one ruptured patient remained in mRS 2 and was not able to go back to work.

Conclusions Endovascular repair of the MCA aneurysm inclosing those with wide neck and complex are not only safe and feasible, but associated with high long-term functional outcome. Therefore, endovascular options must be offered to patients prior to surgical clipping of a MCA aneurysm. Further study may be warranted.

Disclosures Y. Lodi: None. V. Reddy: None.

\section{E-068 AVAILABILITY OF TRANSCRANIAL MOTOR EVOKED POTENTIAL MONITORING IN THE ENDOVASCULAR TREATMENT OF ANTERIOR CHOROIDAL ARTERY ANEURYSMS}

S Hataoka. Neurosurgery, Jake University School of Medicine, Tokyo, Japan
Introduction In neurosurgical operation intraoperative monitoring is now a essential tool for treatment. Expecialy in craniotomy as in clipping and tumor resection. However in the endovascular treatment it is not so often the case. In our institute we used Transcranial motor evoked potential monitoring (TC-MEP) in endovascular treatment from 2014. We will show the effectiveness from our experience.

Methods We studied 15 patients $(\mathrm{n}=16)$ with Anterior choroidal artery (Anch.A) aneurysms who underwent coiling between September 2014 and February 2016. All patients were fully anesthetized by total intravenous Anastasia (TIVA) and TC-MEP were checked after delivering every each coil. The stimulation strength was set at $120 \mathrm{~mA}$. Electromyograms of the bilateral tibias anterior and abductor policies brevis muscle were obtained.

Results TC-MEP of all patients was recorded successfly. No deficits and no decrease in the voltage was seen in the end of the treatment but in 3 cases we experienced significant decrease during the treatment. In 2 cases of these, the decrease was seen just after we inserted the micro catheter into the aneurysm neck. In the other 1 case the decrease was seen when the coil loop prolapsed and covered the Ach.A inflow. Each cases recovered after repositioning. Interestingly the angiographical appearance of the Ach.A didn't change in any case.

Conclusion We were able to treat the Ach.A aneurysms with endovascular surgery using TC-MEP safely and no deficits were seen. There was no change in the angiographic appearance of the Ach.A but TC-MEP voltage decreased in 3 cases. It suspects that TC-MEP could predict the ischemic changes and contribute to the treatment in the endovascular surgery.

Disclosures S. Hataoka: None.

\section{E-069 FLUOROSCOPY TIME AND RADIATION DOSE IN MECHANICAL THROMBECTOMY: A COMPARISON OF TECHNIQUES}

${ }^{1} \mathrm{P}$ Brown, ${ }^{2} \mathrm{M}$ Cobb, ${ }^{1} \mathrm{~T}$ Smith, ${ }^{2} \mathrm{~A}$ Zomorodi, ${ }^{2} \mathrm{~L}$ Gonzalez. ${ }^{1}$ Radiology, Duke University, Durham, NC; ${ }^{2}$ Neurosurgery, Duke University, Durham, NC

\subsection{6/neurintsurg-2016-012589.141}

Introduction/purpose Interventional stroke management has seen a period of explosive growth in the wake of recent trials demonstrating improved outcomes in patients who undergo timely and appropriate procedural management. The two most common interventional techniques involve the use of stent retrieval devices and suction aspiration. In the setting of demonstrable clinical benefit to the patient in these procedures, further exploration of intraprocedural radiation exposure to the patient and operator is warranted. While radiation exposure for the patient in any one procedure is unlikely to produce a clinically-evident adverse event, chronic exposure to the operator may carry significant risk. Our goal is to determine the difference, if any, in fluoroscopy time (FT) and dose area product (DAP) for the use of these devices.

Materials and methods We examined data for interventional stroke management cases performed for M1 segment occlusions at Duke University Medical Center from the period of January 2014 to January 2016 with regards to fluoroscopy time and dose area product. Cases were subdivided into those only utilizing stent retrieval devices (Solitaire $^{\mathrm{TM}}$; Covidien, Dublin, Ireland) and those only utilizing suction aspiration 
devices (Penumbra ${ }^{\circledR}$, Alameda, CA). Mean fluoroscopy time and dose area product, as well as standard deviations were calculated for each technique and compared using Student's ttest.

Results The fluoroscopy time and dose area product for interventional management of vascular occlusions using suction aspiration and stent retriever devices in a selected group of patients is given in the table.

\begin{tabular}{|c|c|c|c|c|c|}
\hline \multicolumn{3}{|c|}{ Suction aspiration } & \multicolumn{3}{|c|}{ Stent retriever } \\
\hline Vessel & $\begin{array}{l}\text { Fluoroscopy } \\
\text { time } \\
\text { (minutes) }\end{array}$ & $\begin{array}{l}\text { Dose area } \\
\text { product } \\
\left(\mathrm{mGy}-\mathrm{cm}^{2}\right)\end{array}$ & Vessel & $\begin{array}{l}\text { Fluoroscopy } \\
\text { time } \\
\text { (minutes) }\end{array}$ & $\begin{array}{l}\text { Dose area } \\
\text { product } \\
\left(\mathrm{mGy}-\mathrm{cm}^{2}\right)\end{array}$ \\
\hline Left M1 & 18.33 & 612188 & Left M1 & 17.25 & 451328 \\
\hline Left M1 & 25.17 & 333391 & Left M1 & 9.8 & 262116 \\
\hline Right M1 & 6.92 & 185136 & Right M1 & 12.85 & 273798 \\
\hline Right M1 & 31.07 & 832479 & Right M1 & 13.78 & 447020 \\
\hline Right M1 & 21.03 & 398619 & Right M1 & 8.4 & 198648 \\
\hline Mean & 20.50 & 472363 & Mean & 12.42 & 326582 \\
\hline $\begin{array}{l}\text { Standard } \\
\text { Deviation }\end{array}$ & 8.99 & 253222 & $\begin{array}{l}\text { Standard } \\
\text { Deviation }\end{array}$ & 3.48 & 115516 \\
\hline $\begin{array}{l}\text { P-value } \\
\text { (FT) }\end{array}$ & 0.048 & & $\begin{array}{l}\text { P-value } \\
\text { (DAP) }\end{array}$ & 0.137 & \\
\hline
\end{tabular}

Conclusion Data from this limited subset of patients suggest a statistically significant difference in fluoroscopy time for mechanical thrombectomies performed with stent retrieval versus those performed with suction aspiration. No significant difference was seen in dose area product data.

The difference in fluoroscopy time between the two techniques may reflect operator comfort rather than intrinsic differences between the two techniques. Notably, however, these data were obtained across multiple operators at our institution, so it may be plausible that these differences are generalizable to technique. It is important to again note that these differences in radiation exposure are unlikely to result in clinical effect in an individual patient, but differences in exposure to the operator over a career may be significant. Further exploration with larger patient samples is warranted.

Disclosures P. Brown: None. M. Cobb: None. T. Smith: None. A. Zomorodi: None. L. Gonzalez: None.

\section{E-070 ENDOVASCULAR TECHNIQUES FOR ACHIEVEMENT OF BETTER FLOW DIVERTER WALL APPOSITION}

${ }^{1} \mathrm{~A}$ Kuhn, ${ }^{1} \mathrm{~K}$ de Macedo Rodrigues, ${ }^{1} \mathrm{M}$ Gounis, ${ }^{2} \mathrm{P}$ Kan, ${ }^{1} \mathrm{M}$ Marosfoi, ${ }^{1} \mathrm{~J}$ Lozano, ${ }^{1} \mathrm{M}$ Perras, ${ }^{1} \mathrm{C}$ Brooks, ${ }^{1} \mathrm{M}$ Howk, ${ }^{1} \mathrm{D}$ Rex, ${ }^{1} \mathrm{~F}$ Massari, ${ }^{1} \mathrm{~A}$ Wakhloo, ${ }^{1} \mathrm{~A}$ Puri. ${ }^{1}$ Division of Neuroimaging and Intervention, Department of Radiology and New England Center for Stroke, University of Massachusetts, Worcester, MA; ${ }^{2}$ Department of Neurosurgery, Baylor College of Medicine, Houston, TX

\subsection{6/neurintsurg-2016-012589.142}

Purpose Flow diverter malapposition as a technical complication with the use of the pipeline embolization device has been described and maybe is associated with delayed ischemic events or potentially delayed life-threatening aneurysm rupture. We describe our endovascular techniques for manipulation of flow diverters in order to achieve proper vessel wall apposition.
Materials and methods We retrospectively analyzed our flow diverter database and included all patients in whom malapposition of the device was detected on follow-up angiography immediately after device deployment. We then evaluated feasibility and technical success of different endovascular approaches aimed to correct the inadequate vessel wall apposition. Successful endovascular techniques for manipulation of the device included use of wires, catheters and additional devices. Final confirmation of flow diverter wall apposition prior to completion of the intervention was performed using 3D multi-planar cone-beam CT reconstruction images.

Results We identified 5 successful endovascular techniques for better flow diverter wall apposition: 1) Use of a wire with a J, pigtail or S-shaped tip passed through the device, 2) Manipulation with a microcatheter, which can be used to press the PED against the vessel wall, 3) Balloon angioplasty of the malapposed segment, 4) Manipulation with an intermediate catheter, which can be used at the proximal edge or within the flow diverter to push the PED against the vessel wall, 5) Placement of another flow diverter within the previously placed FD to better oppose the ends and 6) Placement of an open-cell stent in telescopic fashion across the malapposed portion of the PED (proximal or distal edge). The Neuroform stent with its high outward radial force is an excellent adjunct treatment option to anchor the malapposed flow diverter against the vessel wall while permitting perforator patency.

Conclusion Flow diverter malapposition can be addressed successfully during the interventional procedure using a variety of techniques. This may prevent devastating delayed complications.

Disclosures A. Kuhn: None. K. de Macedo Rodrigues: None. M. Gounis: 1; C; NIH, Medtronic Neurovascular, Microvention/Terumo, Cerevasc LLC, Gentuity, Codman Neurovascular, Philips Healthcare, Stryker Neurovascular, Tay Sachs Foundation, and InNeuroCo Inc. 2; C; Codman Neurovascular and Stryker Neurovascular. 4; C; InNeuroCo Inc. P. Kan: 2; C; Stryker Neurovascular, Covidien, and MicroVention. M. Marosfoi: None. J. Lozano: None. M. Perras: None. C. Brooks: None. M. Howk: None. D. Rex: None. F. Massari: None. A. Wakhloo: 1; C; NIH, Philips Healthcare, Wyss Institute. 2; C; Codman Neurovascular and Stryker Neurovascular. 3; C; Harvard Postgraduate Course, Miami Cardiovascular Institute. 4; C; InNeuroCo Inc, EpiEB and Pulsar Medical. A. Puri: 1; C; Stryker Neurovascular and Covidien. 2; C; Codman Neurovascular, Stryker Neurovascular and Covidien. 3; C; Miami Cardiovascular Institute. 4; C; InNeuroCo Inc.

\section{E-071 INITIAL EXPERIMENTAL RESULT OF A NOVEL, LOW PROFILE STENT FOR ANEURYSM TREATMENT}

I Kan, Y Murayama, K Karagiozov, A Ikemura, I Yuki, H Takao, T Kodama. Neurosurgery, The Jikei University School of Medicine, Tokyo, Japan

\subsection{6/neurintsurg-2016-012589.143}

Introduction Stent assisted coil therapy has been developed for treatment of wide neck aneurysms. However, several reports show that recanalization rate of $10-15 \%$ after therapy is still observed. A novel low profile, flow diverter stent has been developed, and initial experience with it in an experimental wide-neck aneurysm swine model is reported.

Method The novel stent is self-expandable with radiopaque markers on both ends and 0.023 inch inner size compatible 